\title{
SOBRE LAS TAXONOMÍAS DE LO FANTÁSTICO: PARATEXTOS Y AUTOR IMPLÍCITO EN LAS FUERZAS EXTRAÑAS, DE LEOPOLDO LUGONES
}

\author{
José María MarTíneZ \\ Universidad Rey Juan Carlos \\ josemaria.martinez@urjc.es
}

Recibido: 19-06-2020

Aceptado: 29-04-2021

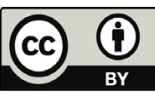

RESUMEN

Los criterios habituales para clasificar los relatos fantásticos han sido el tipo de diégesis del relato y la condición infrasciente del narrador y/o los protagonistas. El presente artículo trata de reivindicar también la función de los paratextos como referencias para esa categorización. Aunque no trata de invalidar los dos criterios citados, sí deja claro que los paratextos, tanto los sincrónicos como los diacrónicos, pueden condicionar y de hecho condicionan el entendimiento de la anécdota o el del tipo de mundo representado en ella. Ya que los paratextos muestran la existencia de lecturas extradiegéticas, contribuyen también a perfilar la figura del autor implícito, otro de los elementos o criterios ausente en la elaboración de estas taxonomías. Tomando como referencias teóricas (con algunas matizaciones) el estudio clásico de G. Genette sobre los paratextos y las sugerencias de W. Booth y W. Schmid sobre el autor implícito, todas estas propuestas se aplican y tratan de ilustrarse recurriendo a Las fuerzas extrañas, de Leopoldo Lugones, una emblemática colección de relatos no miméticos, muy rica en componentes paratextuales y con una complicada historia en lo referido a la clasificación de sus relatos.

Palabras Clave: Leopoldo Lugones; Las fuerzas extrañas; paratextos; autor implícito; taxonomías de lo fantástico. 


\section{ON THE TAXONOMIES OF THE FANTASTIC: PARATEXTS AND IMPLIED AUTHOR IN LEOPODO LUGONES' LAS FUERZAS EXTRAÑAS}

\section{AbStRact}

The usual criteria to define fantastic stories have been the internal diegesis of each and the infra-scient condition of its narrator and/or its characters. Without questioning the validity of such criteria, this article wishes to vindicate the also active role of paratexts when identifying non-mimetic and fantastic fiction. My vindication argues that paratexts (both synchronic and diachronic) can and do shape the understanding of a non-mimetic story as such, as well as the specific type of world the story contains. Since paratexts are also proof of extradiegetic readings of the story, they do contribute to define the figure and role of the implied author, which has been another criterion absent in those taxonomies. Drawing mainly from Genette's classical study of paratexts, and Booth's and Schmid's suggestions on the implied reader, all the above proposals are applied to and illustrated with Leopoldo Lugones' Las fuerzas extrañas, an emblematic collection of non-mimetic stories with plenty of paratextual components and also with a complicated record of the grouping of its stories.

KEY WORDS: Leopoldo Lugones; Las fuerzas extrañas; paratexts; implied author; classifications of fantastic literature.

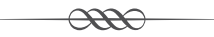

\section{El problema y un (BREVÍ́simo) ESTADO DE LA CUESTión}

El presente trabajo trata de reivindicar la intervención del autor —en cuanto instancia distinta al narrador- y la funcionalidad de los paratextos como criterios para la clasificación de la literatura no mimética en general y de la fantástica en particular. Es, me parece, una reivindicación necesaria pues las principales referencias a la hora de elaborar esas taxonomías han solido ser la narratología de la diégesis misma, el tipo o actitud del narrador y el efecto de lo narrado sobre el lector. Adelanto también que no pretendo tanto modificar las definiciones existentes, como llamar la atención sobre la importancia de estos dos agentes externos a la narración (pero no al lector) a la hora de condicionar la lectura de lo fantástico. Y es que no hay que olvidar que los paratextos (y con ellos el autor) están siempre presentes en el acto de lectura histórica, ya que son lo que hace «digerible» un texto que nunca se ofrece en estado 
puro. Como afirma Philippe Lejeune, el paratexto «commande toute le lecture» (apud Genette, 2001: 8) y remite al nivel más empírico y pragmático del texto, pues es el autor y no el narrador quien tiene acceso a los paratextos y, con ello, quien realmente presenta el texto al lector. En otras palabras, y en lo que ahora interesa, es el autor (a menudo junto al editor) quien a través de los paratextos puede hacer que una anécdota pueda leerse como algo más o menos verosímil o más o menos extraordinario.

El estudio sistemático del nivel paratextual de las narraciones fantásticas es más bien inexistente, ${ }^{1}$ y en el curso de esta investigación sólo he encontrado unas muy pocas contribuciones al respecto, casi todas ellas referidas a la literatura anglófona y, más en concreto, a la ciencia ficción o al género gótico. Curiosamente, los dos casos más útiles insisten en mostrar las conexiones entre los paratextos y el hiperrealismo de las narraciones no miméticas. ${ }^{2}$ Así Anna Ojalahti (2017) recurre al discurso más objetivista de los epígrafes para mostrar cómo estos pueden incrementar la verosimilitud en textos maravillosos o de «high fantasy», en concreto en la novela Fool's Quest, de Robin Hobb (2015). Por su lado Imogen Mathew (2018: 89-93), a propósito de Dracula (1897), comenta cómo los prefacios son también espacios privilegiados en los que el autor del libro y / o del paratexto negocia con el lector la historicidad de lo narrado. ${ }^{3}$ En cualquier caso y a pesar de su utilidad, esto son ejemplos relativamente limitados para mi objetivo, pues, como detallo a continuación, Las fuerzas extrañas (en adelante LFE) contiene una gama tan amplia de paratextos que realmente puede convertirse en una referencia para el estudio de lo paratextual en cualquier volumen de relatos, sean estos realistas o fantásticos.

\section{MARCO TEÓRICO Y CONCEPTUAL}

En cuanto a los conceptos teóricos empleados en mi trabajo, el primer grupo procede principalmente del estudio clásico de Gérard Genette (2001)

1 Una muestra elocuente puede ser el trabajo de Millet y Labbé (2005), que, a pesar de su intención totalizante y organicista de la historia, la temática y la narratología de lo fantástico, no dedica ninguna consideración a los paratextos de este tipo de relatos.

2 Más adelante me refiero al trabajo de Andrea Castro (2003), que sí comenta ligeramente la dimensión paratextual de uno de los relatos de LFE.

3 Como interesante y a la vez curiosa adición, puede sumarse el estudio de Ulrike Altman et al. (2014), más psicológico que literario, pero también más científico y experimental. Según este trabajo los paratextos producirían una reacción diferente en el cerebro del lector ya en los momentos previos a la lectura de la diégesis: «Factual works — concluyen — relate to the cooperation and alignment of individuals in the real world, whereas fictional works follow primarily the task of imagination and simulation» (2014: 28). 
sobre los umbrales del texto literario. ${ }^{4}$ Como se recordará, Genette llama «paratexto» a todo aquel elemento textual o gráfico empleado para acompañar y hacer asimilable el texto central, que muy rara vez suele presentarse «desnudo» (2001: 7-18). A su vez los paratextos podrían agruparse en peritextos y epitextos. Los primeros serían elementos como los títulos, los epígrafes, las ilustraciones o las notas $\mathrm{y}$, a su vez, pueden clasificarse en peritextos autoriales (si proceden de la mano del autor) o peritextos editoriales (si proceden de la mano del editor). Esta segunda clasificación tampoco sería rígida, pues existiría una zona intermedia donde cabría la colaboración entre autor y editor o donde el autor podría operar como editor. Por su lado los epitextos serían aquellos «textos» ausentes en la presentación física del texto central pero útiles también para explicar su génesis o su significado; como ejemplos estarían las entrevistas con el autor, las reseñas, las versiones gráficas o audiovisuales, etc. Algunos estudios posteriores han añadido matices a esta clasificación que el propio Genette presentó como provisional (v. Ojalahti, 2017: 33). Como se verá, LFE puede también ayudar a ampliar esas nomenclaturas y clasificaciones, pues incluye paratextos omitidos $u$ obviados en el estudio de Genette como pueden ser las diferentes versiones impresas de un mismo texto, las pruebas de imprenta, las advertencias, etc. En cualquier caso y aunque en ocasiones sería más preciso emplear el término de «peritextos», en las páginas que siguen prefiero emplear el término general de «paratexto», por ser el más conocido y porque esa distinción resulta innecesaria en mi propuesta.

Para el concepto de autor, mis principales referencias son el «implied author» o autor implícito sugerido por Wayne Booth (1961: 71-76) y por Schmid (2013), diferente de lo que aquí voy a llamar «autor histórico» o «autor empírico». ${ }^{5} \mathrm{El}$ «autor implícito» sería entonces el reverso del «lector implícito» de la teoría de la recepción; si este último es la instancia abstracta o proceso de recepción derivado de la lectura de un texto determinado, el autor implícito

4 La amplia bibliografía consultada al respecto no suele modificar sustancialmente las aportaciones de Genette, pues son más bien reflexiones teóricas sobre las mismas (Maclean, 1991), o aplicaciones de sus nomenclaturas a obras más específicas (Sabia, 2005).

5 Advierto que el concepto de «autor implícito» no siempre resulta fácil de definir y que por ello los diccionarios de narratología suelen incluir varias acepciones, muy distintas entre sí. En concreto, el estado de la cuestión que presenta Schmid (2013) es tan interesante como provisional, en el sentido de que, al final, sería una categoría entendible a la vez como abstracta o como biográfica o formalista, dependiendo de los aspectos que se prioricen. Esa misma dificultad justifica que categorías como las que voy a usar aquí («autor implícito», y «autor empírico») no deban entenderse como compartimentos estancos sino como vasos comunicantes y que, a veces, por lo mismo, puedan referirse al mismo sujeto aunque contemplado en funciones diferentes. En cualquier caso, lo que creo que mi trabajo dejará claro es que el ámbito de los paratextos es un espacio privilegiado para comentar las operaciones de esa instancia peculiar que es el autor en cuanto condicionado o incluso determinado por su propia creación. Sobre la plurisignificación del concepto «autor implícito», v. también Reis y Lopes (2002: 28-29). 
sería la instancia personal y al mismo tiempo abstracta generada en el proceso de escritura de un texto concreto. Como afirma Booth, el autor implícito «chooses, consciously or unconsciously, what we read; we infer him as an ideal, literary, created version of the real man; he is the sum of his own choices» (1961: 74-75). De esta definición, quizá lo más interesante para el caso de LFE sería la matización "consciously or unconsciously», en el sentido de que la figura del autor implícito reúne tanto las elecciones que el autor empírico lleva a cabo activamente al redactar un texto concreto, como las obligaciones que las convenciones literarias imponen al autor empírico durante el proceso de redacción del texto y que este autor debe obedecer más o menos irremediablemente.

Aplicada esta dualidad autorial a LFE, su autor implícito no sería tanto el Leopoldo Lugones cuya biografía - literaria y extraliteraria - se extiende desde 1874 hasta 1938, sino el Leopoldo Lugones que es única y exclusivamente productor y producto del volumen titulado Las fuerzas extrañas, publicado en 1906 y configurado en sus contenidos temáticos, ideológicos y formales de un modo diferente a otras obras de Lugones. El autor implícito de LFE se distinguiría por tanto del Lugones del mismo momento histórico pero sujeto de otras labores, y, por supuesto, de los diversos y numerosos narradores de los relatos de $L F E$, que no pueden ser autores de ningún componente paratextual o externo a su propia narración. ${ }^{6}$ Como veremos, este autor será por un lado el ejecutor de los umbrales o de la presentación de los textos de LFE, pero también el resultado de las convenciones literarias que operan sobre el autor empírico en ese momento de la presentación del texto ante el lector histórico. Si se quieren extrapolar estos conceptos y aceptar la llamada «muerte del autor», el autor implícito sería más un autor abstracto que empírico, más el resultado de las estrategias de producción y visibilización de un texto literario que el ejecutor de las mismas. A lo largo del trabajo y si no se hacen especificaciones, emplearé el sintagma «autor empírico» para referirme bien al autor histórico en general o bien a la persona de Leopoldo Lugones en particular.

Con esta serie de conceptos lo que queda claro es que el nivel paratextual es diferente del nivel de la diégesis propiamente dicho, ya que los paratextos serían un acto de locución primera y de intención pragmática (Maclean, 1991: 274),

6 Durante mi investigación pensé también en incluir en este trabajo las conexiones entre estos dos tipos de autor y los diferentes tipos de narradores de $L F E$, pues por la variedad de narradores y sus diferentes interacciones con lo fantástico habrían dado lugar a reflexiones de indudable interés. Sin embargo, por razones de espacio y también para ahondar más en el terreno casi virgen de las correlaciones entre los paratextos y lo fantástico, he preferido dejar esas correlaciones para un posterior trabajo. Sobre el narrador como posible autor de uno de los paratextos de LFE (las notas), me extiendo al comentar el último relato del libro. 
mientras que la diégesis sería un acto de locución posterior y también un producto final y mediatizado, con una carga pragmática muy distinta de la paratextual. Con los paratextos el lector histórico se encuentra ya en un mundo intermedio, pues todavía no ha entrado en el universo ficcional, aunque, de hecho, ya ha empezado a abandonar su mundo histórico. Al mismo tiempo es en ese mundo intermedio donde se producen los primeros contactos con el universo ficcional concreto que el lector va a visitar. Los umbrales constituyen entonces un ámbito de alta rentabilidad pragmática y de alta «contaminación» en el proceso de lectura de la diégesis, ya que en ellos se produce una intensa serie de intercambios más o menos conscientes entre autores, editores y lectores que van a determinar la recepción concreta de cada texto. Es en este ámbito donde se fragua y concreta el horizonte de expectativas propio de cada género literario o bien, en lo que aquí interesa, donde el lector empieza percibir el carácter realista o no mimético de la ficción. En este sentido, habría que recordar entonces que no sería el narrador ni los narradores quienes presentan su narración al lector sino el autor implícito, es decir, el autor empírico en su dimensión performativa concreta en esa obra. ${ }^{7}$ Desde esta perspectiva la anécdota estaría antes mediatizada por el autor que por el narrador, que por ser un ente de ficción resultaría una criatura de segundo nivel y que, por tanto, no puede conectarse con el nivel primario del lector histórico. Como en el caso de la literatura mimética, la anécdota fantástica necesita entonces de la mediación inicial de la instancia autorial y/o editorial, y el paratexto sería por ello el primer punto de contacto del efecto de lo fantástico en el lector, previo por consiguiente a la lectura efectiva del discurso narrativo.

\section{El corpus}

En cuanto a $L F E$, se trata de un volumen casi ideal para un análisis de este tipo pues, aparte de su trascendencia en la historia de las literaturas hispánicas, su «fantasticidad» ha sido uno de los motivos comentados continuamente por la crítica, con resultados más bien divergentes. Por otro lado, la abundancia y singularidades de sus paratextos se refieren tanto al volumen como tal como a todos los relatos que lo integran considerados individualmente. En cuanto a la fantasticidad de LFE, prácticamente todos los estudios proponen este aspecto como uno de los rasgos definidores del libro. En ese conjunto estas lecturas van desde quienes aceptan automáticamente la entidad fantástica de todos y cada

7 Tampoco me parece exacto afirmar que los paratextos pueden ser obra del llamado «narrador autorial», dado que este, al fin y al cabo, sigue siendo un actante propio de la diégesis y no del mundo histórico. 
uno de los relatos (Speratti Piñero, 1957) hasta quienes lo rechazan abiertamente (Naharro-Calderón, 1994; Linde, 2014) o quienes se sitúan en una posición intermedia o matizan esas clasificaciones (Quereillac, 2016). En general, esta divergencia se explica por el empleo de la tipología todoroviana o también por la propuesta de una doble lectura para el libro, algo que, por otro lado, parece inherente al mismo (Ruiz Barrionuevo, 1995; Kônig, 1984). En cuanto a esta doble lectura, un grupo de críticos se habría fijado principalmente en los cuentos de la primera parte del libro y habría obviado el texto final del volumen (el «Ensayo de una cosmogonía en diez lecciones») por considerarlo más filosófico que ficcional. Un segundo grupo (más numeroso) habría preferido tener en consideración el conjunto y prestar al texto final un valor referencial y explicativo para el resto (Scari, 1964; Zuckerman, 1975; Ghiano, 1985). Desde esta perspectiva, y dado que el «Ensayo» ${ }^{8}$ puede verse como la explicación teórica de los argumentos de los doce primeros relatos, el libro en su conjunto no sería tanto una obra adscribible a lo fantástico-puro sino a lo extraño ya que, en definitiva, todas las incógnitas de los relatos de la primera parte encontrarían su respuesta en el tipo de universo descrito en el ensayo final. Aunque, en principio, mi artículo comparte esta última valoración de la fantasticidad de $L F E$, también es cierto que asume la posibilidad de una doble lectura de sus relatos, es decir, en cuanto textos individuales o en cuanto parte de un conjunto. Es por esta razón y especialmente si se considera la historia editorial del volumen, que la adscripción del libro a la categoría de lo extraño no deja de necesitar importantes matizaciones.

En lo referido al elenco de componentes paratextuales del libro, este incluye tanto los habituales de cualquier volumen de relatos (título general, índice, título de cada relato, etc.) como otros más específicos, tales como la advertencia de la segunda edición del libro, los subtítulos de cuentos como «La lluvia de fuego» o «El origen del diluvio», los epígrafes en dos de ellos («La lluvia»y «Viola acherontia»), el cambio de título en tres de esos relatos («Un fenómeno inexplicable», «Viola», «El escuerzo»), las ilustraciones que acompañaron a algunas versiones de «La fuerza Omega» $\mathrm{O}$ «El milagro de san Wilfrido», o el contexto más inmediato de sus versiones periodísticas. Además, hay que incluir el «Ensayo» que cierra el libro, pues aparte del título y los subtítulos de cada una de las diez «lecciones», presenta unas notas explicativas que casi requerirían un capítulo aparte, por problematizar de forma muy singular las correlaciones entre autor empírico, autor implícito y narrador. Como puede ya adivinarse, en todos estos paratextos va a ser obvia la existen-

8 En adelante, el título de los diferentes textos y relatos de LFE se nombrarán por su primera o primeras palabras, salvo en su aparición inicial o cuando pueda existir riesgo de ambigüedad o confusión. 
cia de esas negociaciones entre autor y lector cuando este trata de acceder a la diégesis y comienza a plantearse si debe leerla como un acontecimiento probable o extraordinario.

Para conocer la dimensión paratextual de LFE hay que comentar entonces la historia editorial del volumen. Al respecto y con los datos disponibles hasta ahora y en función de la fecha y lugar de publicación de la primera o primeras versiones conocidas, podrían establecerse dos grupos de cuentos. El primero sería el de aquellos publicados inicialmente en la prensa periódica y recogidos después, con variantes de mayor o menor relevancia, en la primera edición el volumen (Lugones, 1906a). El segundo grupo lo constituirían los textos cuya primera publicación conocida es la del volumen de 1906 y que habrían pasado a la segunda edición (1926) sin variaciones de mayor importancia. ${ }^{9}$ En cualquier caso hay también que aceptar que la cronología y la procedencia periodística de los textos son por ahora provisionales, aunque, al mismo tiempo, la exhaustividad de las investigaciones parece indicar que los datos presentes no van a cambiar mucho y que, por tanto, pueden tomarse como hipótesis de trabajo. ${ }^{10}$ En los cuadros que siguen los relatos del primer grupo se ordenan cronológicamente, si bien se presentan una o dos fechas posibles, en función de los datos ofrecidos por la bibliografía sobre Lugones. Se marcan en color diferente aquellos relatos con variantes en sus títulos:

\begin{tabular}{|l|l|}
\hline Título del cuento en el libro & Título del cuento en publicaciones periódicas \\
\hline El milagro de san Wilfrido & $\begin{array}{l}\text { El milagro de san Wilfrido: El Tiempo, 15 de abril } \\
\text { de 1897, y Caras y caretas, mayo 1906. }\end{array}$ \\
\hline El escuerzo & $\begin{array}{l}\text { Los animales malditos: El Tiempo, } 10 \text { de diciembre } \\
\text { de } 1897 .\end{array}$ \\
\hline La metamúsica & La Meta Música: Tribuna, 29 de junio de 1898. \\
\hline El Psychon & $\begin{array}{l}\text { El Psychon: Tribuna, } 31 \text { de enero de } 1898 \text { y/o } \\
\text { también } 30 \text { de agosto de } 1898 .\end{array}$ \\
\hline
\end{tabular}

9 En este sentido hay que añadir también que la crítica apenas se ha ocupado de la preparación inmediata de $L F E$, es decir, del proceso de recuperación y corrección de manuscritos o de ediciones previas de los cuentos. De la misma manera, es de notar la ausencia de documentación referida a la recepción inmediata del volumen y a la publicación en prensa de los cuentos y del «Ensayo».

10 Las fechas de publicación de los textos están tomadas de los diferentes trabajos sobre la producción de Lugones (Berg, 1968; Lermon, 1969; Ciruti, 1975; Fletcher, 1981) y de otras referencias como las proporcionadas por Barcia (1981) o por el hijo del propio autor de LFE (Lugones [hijo], 1963). En cuanto a la exhaustividad de esas investigaciones, las búsquedas más recientes han resultado igualmente infructuosas (Martínez, 2019; Martínez, Godínez y Vargas, 2019; Nájera Ramírez, 2019). 


\begin{tabular}{|l|l|}
\hline Título del cuento en el libro & Título del cuento en publicaciones periódicas \\
\hline Un fenómeno inexplicable & $\begin{array}{l}\text { La Lycantropía (Cuento): Philadelphia, 7 de } \\
\text { septiembre de 1898. }\end{array}$ \\
\hline La estatua de sal & $\begin{array}{l}\text { La estatua de sal: Tribuna, } 17 \text { de mayo de } 1898 \text { y/o } \\
\text { también septiembre de } 1898 .\end{array}$ \\
\hline Viola Acherontia & $\begin{array}{l}\text { Acherontia Athropos: Tribuna, } 31 \text { de enero de } 1898 \\
\text { o } 1899)\end{array}$ \\
\hline La fuerza Omega & La fuerza Omega: El Diario, diciembre de 1905 \\
\hline
\end{tabular}

El segundo grupo lo constituirían los relatos restantes, cuya primera aparición conocida es en LFE; por lo mismo, el cuadro correspondiente resulta bastante sencillo y hasta innecesario:

\begin{tabular}{|l|l|}
\hline Título del cuento en el libro & Título del cuento en publicaciones periódicas \\
\hline Yzur & \\
\hline El origen del diluvio & \\
\hline Los caballos de Abdera & \\
\hline La lluvia de fuego & \\
\hline $\begin{array}{l}\text { Ensayo de una cosmogonía } \\
\text { en diez lecciones }\end{array}$ & \\
\hline
\end{tabular}

Con estos dos cuadros puede ya intuirse que Lugones habría llevado a cabo una relectura de aquellos cuentos aparecidos primeramente en publicaciones periódicas, y que esa relectura habría afectado de manera diferente a los relatos seleccionados para su inclusión en el libro. ${ }^{11}$ Así, unos habrían sufrido unas modificaciones más profundas, que incluirían cambios de título, eliminación o adición de epígrafes, etc.; otros, especialmente los más cercanos a la fecha de 1906, habrían permanecido casi inalterados. Así pues, en el libro las divergencias entre estos y otros paratextos hablarán tanto de la relectura que Lugones hizo de sus relatos, como de la nueva presentación que su autor quiso para ellos. Lo mismo puede decirse a propósito de la segunda edición del volumen, a la que Lugones añadió también algunos nuevos paratextos.

11 Para más detalles sobre el proceso de selección, descarte y preparación de esos textos, así como sobre las correcciones y variantes entre las versiones periodísticas de los diferentes relatos, v. Martínez (2019) y Martínez, Godínez y Vargas (2019). 


\section{Entre lo extraño y lo fantástico}

En cuanto a la intención temática o ideológica de $L F E$, parece seguro que el libro es en el fondo una ficcionalización de las ideas teosóficas que Lugones defendía por entonces y que el volumen era una peculiar versión de la Doctrina Secreta de Helena P. Blavatsky (Hewitt, 1979; Linde, 2014; Quereillac, 2016; Martínez, 2019). En lo que aquí interesa, esa doctrina y la concepción del universo propuesta en ella quedarían explicitadas sobre todo en el «Ensayo» final y en algunos relatos particulares del libro, especialmente en los ocultistas («El origen») o en los paracientíficos que asumen una concepción analógica del universo («La fuerza», «La metamúsica»). De la misma manera, el «Ensayo» sería la explicación última de las anécdotas de los doce primeros cuentos (Ghiano, 1985; Scari, 1964: 165; Barcia, 1981: 43), es decir, propondría un universo donde sí habría explicación para los acontecimientos extraordinarios de cada una de las anécdotas particulares y en el cual, por tanto, no cabrían los vacíos narratológicos ni los enigmas irresueltos. En otras palabras, esos relatos que individualmente podrían ser considerados fantástico-puros o maravillosos serían, leídos en el conjunto de libro y con el «Ensayo» como trasfondo, extraños o incluso miméticos, ya que podrían integrarse perfectamente en la visión efectiva que del universo tendría el autor del libro. Como ejemplos concretos, las fuerzas o energías que explican la animación de la mano de san Wilfrido, la humanización del escuerzo o la identidad entre la música y los colores, serían las mismas que se alojan en el universo analógico del «Ensayo» o de «La fuerza», y por tanto las que explican las alteraciones de las leyes del universo que alojan todas y cada una de las anécdotas. A pesar, pues, de no darse en un mundo entendido en clave positivista, esas anécdotas serían tan posibles y verificables como las alojadas en cualquiera de los mundos del realismo mimético. Como texto ubicado al final de este conjunto de relatos, el «Ensayo» funcionaría entonces de manera similar a las explicaciones que en relatos extraños o en muchos relatos policiacos cierran la narración para justificar el acontecimiento que al comienzo de la misma se acontecía también imposible.

Dado entonces que algunos de esos relatos fueron publicados con anterioridad a $L F E$ es decir, desconectados del «Ensayo» y en un diferente contexto inmediato (el del periódico que los recogió), proponer una etiqueta diferente a la de relatos «extraños» puede también estar justificada, especialmente si se considera que alguno de esos relatos, vistos individualmente, podrían adscribirse sin problemas al grupo de lo fantástico-puro. El cuadro que sigue sugiere entonces la etiqueta propia de cada relato de LFE considerado individualmente. En cuanto a lo fantástico-puro el principal criterio empleado sería el de la existencia die- 
gética de la ruptura de una ley natural, ruptura formulada como un enigma irresuelto. Como criterios secundarios se emplean otros como el hiperrealismo de esos relatos, la participación de un narrador infrasciente o la presencia del discurso de la credibilidad. ${ }^{12}$ Para otras etiquetas como lo extraño o lo maravilloso tomo como referencia la clasificación básica de Todorov (1975). El cuadro distingue también entre mundo narrado y tipo de argumento, ya que así se refleja mejor el entendimiento de lo fantástico como modo de relato y se subsanan también las frecuentes confusiones habidas al comentar los cuentos de LFE. ${ }^{13}$

\begin{tabular}{|l|l|l|}
\hline Título & Tipo de mundo narrado & Tipo de argumento \\
\hline La fuerza Omega & extraño & paracientífico \\
\hline La lluvia de fuego & maravilloso & bíblico-ocultista \\
\hline Un fenómeno inexplicable & fantástico & ocultista \\
\hline El milagro de san Wilfrido & maravilloso & hagiográfico \\
\hline El escuerzo & fantástico & legendario \\
\hline La metamúsica & extraño & paracientífico \\
\hline El origen del diluvio & fantástico & ocultista \\
\hline Viola Acherontia & extraño & paracientífico \\
\hline Yzur & extraño & paracientífico \\
\hline La estatua de sal & maravilloso & bíblico-hagiográfico \\
\hline Los caballos de Abdera & maravilloso & mitológico \\
\hline El Psychon & extraño & paracientífico \\
\hline $\begin{array}{l}\text { Ensayo de una cosmogonía } \\
\text { en diez lecciones }\end{array}$ & mimético-realista & filosófico \\
\hline
\end{tabular}

12 Obviamente, estos criterios son una suma de los propuestos en trabajos ya clásicos y conocidos como los de Todorov (1970), Barrenechea (1972), Jackson (1981), Roas (2001), Morales (2004), Martínez (2010) y muchos otros.

13 La ausencia de esta diferenciación entre tipo de mundo narrado y tipo de argumento ha sido una de las razones principales de la confusión y complicada historia de las taxonomías y clasificaciones de los relatos del libro. Como resumen, interesa recordar que el punto de partida de esas clasificaciones fue el trabajo de Speratti Piñero (1957), que establecía tres tipos de relatos según la referencialidad de sus argumentos (cientifistas, legendarios y mixtos). Con diferentes matices, esta clasificación habría continuado en trabajos como los de Zuckerman (1975), Semilla (1985) o Pampa Arán (2000). Otras clasificaciones habrían buscado identificar una serie de criterios más bien abstractos, como la tipología de personajes principales (Linde, 2014), las ideas teosóficas (Quereillac, 2016) o el empleo de la ciencia (López, 2004). Otros, finalmente, habrían tratado de combinar los dos tipos de criterios (Barcia, 1981; Speck, 1976). Obviamente, mi clasificación puede admitir muchas matizaciones, pero creo que en general sirve para efectuar una lectura de LFE mucho más ordenada que las realizadas hasta ahora, que no han solido aplicar más o menos sistemáticamente las aportaciones de las teorías de lo fantástico más recientes. 
La primera conclusión derivable de esta clasificación sería quizá el hecho de que la cosmovisión ofrecida por los doce primeros relatos, considerados como independientes del «Ensayo», sería no mimética. ${ }^{14}$ Salvo el «Ensayo», los demás relatos ofrecen un tipo de mundo que puede ser maravilloso, fantástico o extraño y donde el materialismo o la lógica racionalista no pueden producir un marco apropiado para la representación de todo lo real. Obviamente, nos encontramos ante una de las líneas preferidas por los escritores modernistas, es decir la de la reacción al pragmatismo burgués y de reivindicación de la imaginación, del exotismo espacial y temporal y de las causalidades más bien ilógicas. En concreto, en el caso de Lugones y según formula en el «Ensayo», el mundo de esos argumentos pertenecería a lo que él llama «espiritualismo», concepción que estaría a medio camino entre el materialismo burgués y el super-naturalismo de las religiones históricas (1996: 274). En este sentido el hecho de que el relato final del volumen, el «Ensayo», sea mimético-realista no debe considerarse casual sino algo más bien intencionado, pues así quedaría justificado su carácter de explicación objetiva y fiable de los argumentos de los primeros doce relatos.

Quizá las novedades más interesantes en mi clasificación son las referidas a los cuentos paracientíficos y a los tres fantástico-puros, en especial «El escuerzo», que han solido bautizarse con etiquetas diferentes a las mías. Así los paracientíficos se han identificado a menudo como los más característicos y originales del volumen, por tratarse quizá de unos argumentos únicos o al menos muy singulares en la narrativa modernista hispánica. Son también los más numerosos y, por ello, los que a menudo han servido para asignar el tono al libro o incluso para considerarlo una de las primeras muestras de la ciencia ficción hispánica (Haywood Ferreira, 2011). Obviamente las etiquetas de «paracientíficos» o «fantaciencia» se refieren a su argumento, pero no al tipo de mundo narrado pues, a mi juicio, no son ni propiamente fantásticos ni propiamente relatos de ciencia ficción. No serían fantásticos por no presentar discontinuidades argumentales ni vacíos narratológicos, ya que todo su conjunto de causalidades (independientemente de si son o no ficticias en el mundo histórico) quedan explicadas y visibles en la diégesis interna del relato; todos ellos presentan mundos cerrados y autoexplicados por el narrador o por uno de los personajes. Tampoco me parecen relatos de ciencia fic-

14 Obviamente, el «Ensayo» es en puridad un relato, ya que cuenta con una diégesis (si bien mínima) y componentes estructurales como personajes, espacio, tiempo o relaciones de causalidad. Es evidente también que su contenido filosófico es más extenso que la mímesis propiamente hablando y que, por tanto, su etiquetación como «ensayo» queda relativamente justificada. 
ción, ya que su anécdota está anclada en el presente histórico del autor empírico y no se producen viajes a mundos alternativos ni aparecen tampoco personajes o causalidades diferentes a las conocidas por el autor. Igualmente, el «novum» propio de estos relatos (las máquinas o experimentos y las teorías que sustentan sus funcionamientos) son realmente teorías científicas contemporáneas a Lugones y aceptadas por este como hipótesis verificables y no como invenciones imaginarias. ${ }^{15}$ Que al final en varios de esos relatos el experimento resulte en una desgracia es precisamente una confirmación del funcionamiento de esas leyes extrañas y no una interrogación sobre la existencia de las mismas.

Por su parte, lo que llamo fantástico-puro quedaría manifiesto en tres de esos cuentos, que serían «Un fenómeno inexplicable», «El escuerzo»y «El origen del diluvio». En los tres se representa la ruptura de una ley natural, como son respectivamente la falta de correspondencia entre el objeto y su sombra, la humanización de un animal y la comunicación entre mundos discontinuos. En los tres esa ruptura se presenta también como problemática, como lo muestra, por ejemplo, la conclusión de la anécdota en su momento climático y cerrado a todo tipo de respuesta. Algunos recursos más específicos de lo fantástico serían más visibles en alguno de esos relatos en particular. Así, la presencia de un narrador infrasciente o el recurso al hiperrealismo es más obvio en «Un fenómeno inexplicable», mientras que la aparición del personaje o narratario escéptico se percibe mejor en «El escuerzo», con la Julia que escucha al metanarrador, o en «El origen», con el personaje de Mr. Skinner, que es quien encuentra la prueba material que desautorizará su incredulidad (1996: 151, 179-180). Como puede notarse, se trata de anécdotas, recursos narratológicos y tipos de mundos representados que pueden adscribirse sin recelo alguno al modelo de lo fantástico-puro, siempre que obviemos que, leídas a la luz de la cosmogonía expuesta en el «Ensayo», las rupturas de las leyes naturales de dichas anécdotas dejan de ser problemáticas.

\section{LOS PARATEXTOS DEL LIBRO}

En cuanto a la paratextualidad concreta de LFE, podría proponerse un cuadro que agrupase en tres conjuntos el total de sus paratextos. El primer grupo lo conformarían aquellos que afectan a todo el libro, el segundo los re-

15 Sobre este aspecto y en particular sobre el distanciamiento entre lo fantástico, la ciencia ficción y las «fantasías científicas» o la «fantaciencia», v. sobre todo Gasparini (2008: 143, 2012) y Quereillac (2016). 
feridos a los doce relatos particulares de la primera parte y el tercero los referidos al «Ensayo». Con los datos bibliográficos conocidos hasta ahora el cuadro resultante sería el siguiente:

\begin{tabular}{|l|l|}
\hline Corpus afectado & Paratextos correspondientes \\
\hline Todo el libro & Título, índice, advertencia de la segunda edición. \\
\hline $\begin{array}{l}\text { Los doce cuentos } \\
\text { de la primera parte }\end{array}$ & $\begin{array}{l}\text { Títulos, subtítulos («La lluvia de fuego»; «El origen del di- } \\
\text { luvio»); epígrafes («La lluvia de fuego»; «Viola acheron- } \\
\text { tia»); cambios de título («Viola acherontia», «Un fenómeno } \\
\text { inexplicable»); correcciones del texto («Viola acherontia», } \\
\text { «a estatua de sal», «El psychon», «Un fenómeno inexpli- } \\
\text { cable»); ilustraciones y contexto periodístico («El milagro } \\
\text { de san Wilfrido»; «La fuerza Omega»). }\end{array}$ \\
\hline «Ensayo» & Título, subtítulos e intertítulos, notas explicativas. \\
\hline
\end{tabular}

\section{1 Paratextos que afectan a todo el volumen}

\subsubsection{Título del libro}

En cuanto al título del libro, y siguiendo la terminología de Genette (2001: 72-79), este sería temático y no remático, por aludir a la referencialidad externa de los cuentos y no tanto al formato textual del volumen. Sería entonces la interpretación que el autor implícito hace del contenido de su volumen y, por ello, la expresión de su lectura del contenido del mismo y la que, en principio, desea también que tengan sus lectores. Igualmente se trataría de un título «federal» (Genette, 2001: 54-58), por ser colectivo y aunar lo que en los periódicos o en las publicaciones previas aparecía separado e independiente, y por generar también una lectura nueva de esos relatos aislados, leídos ahora en un contexto inmediato nuevo y diferente. Habría habido, pues, una resemantización de los cuentos, por aparecer ahora englobados bajo un título ajeno a la primera aparición de cada uno de ellos; dicha resemantización - y esto es importante- parece haberse debido a la intertextualidad de LFE con la Doctrina Secreta de Blavatsky. En concreto, el título del libro de Lugones parece proceder de una serie de capítulos de la Doctrina secreta que recogen ejemplos de investigaciones sobre diferentes energías y en especial sobre la que Blavatsky denomina «coming force», es decir, las fuerzas nuevas o reciente- 
mente descubiertas por las ciencias (1978: I, 490-557). ${ }^{16}$ Esto explica, por ejemplo, que tan «extrañas» sean las fuerzas o energías de los relatos maravillosos o mitológicos del libro como las de los relatos paracientíficos. Así visto, el total del mundo de LFE sería «extraño», es decir, y por ironías del destino, identificado por su título con el mismo adjetivo clasificatorio de las taxonomías de Todorov. El mundo de LFE puede entonces alojar acontecimientos aparentemente extraordinarios, pero para los que cabe también una explicación que no es solo literaria sino también «científica».

\subsubsection{El índice}

En cuanto al índice general del libro, pueden sugerirse dos lecturas. La primera, y seguramente la más interesante, sería la disposición simétrica y también concéntrica del conjunto de los relatos, que se correspondería con la concepción analógica del universo teosófico. ${ }^{17}$ En este sentido el índice -y con ello el conjunto del libro - sería una metonimia o una materialización de ese universo. Esta hipótesis afirma que el índice total estaría organizado en dos partes simétricas, compuestas respectivamente de doce textos, es decir, de los doce relatos de la primera parte y de los doce textos del «Ensayo» (las diez lecciones, más el proemio y el epílogo). A su vez, los doce relatos de la primera parte estarían organizados en parejas concéntricas correlacionadas por sus motivos temáticos o argumentales. Así, la primera pareja la constituirían el primer y el duodécimo relatos, es decir, «La fuerza Omega» y «El Psychon», que son dos cuentos paracientíficos; la segunda la conformarían el segundo («La lluvia de fuego») y el undécimo («La estatua de sal»), o sea, dos relatos de intertextualidad bíblica; la tercera la formarían el tercer relato («Un fenómeno inexplicable») y el décimo («Yzur») y estaría fundamentada en la militancia antidarwinista de la Teosofía; la cuarta la integrarían los relatos cuarto y noveno («El milagro de san Wilfrido» y «Viola Acherontia») y estaría vertebrada en torno a un simbolismo vegetal complementario; la quinta la conformarían el quinto y octavo relatos («El es-

\footnotetext{
16 Al respecto hay que recordar también que durante la hiperactividad cientificista del XIX, tampoco estaban siempre claras las fronteras entre las ciencias positivas y las ciencias ocultas, y que fueron bastantes los científicos e intelectuales - Lugones entre ellos- que se movían en los dos ámbitos sin considerarlos incompatibles (Gasparini, 2008: 143; Gasparini, 2012: 59; Quereillac, 2016).

17 Para más detalles sobre esta propuesta v. Jensen (1975), que comenta sobre todo la relación entre las dos partes del índice, y Martínez (2019), que se fija en la correspondencia entre los relatos de la primera parte.
} 
cuerzo»y «Los caballos de Abdera»), unidos por el protagonismo de unos animales humanizados; y la sexta la integrarían los relatos sexto y séptimo («La metamúsica» $\mathrm{y}$ «El origen del diluvio»), unidos por la propuesta de un universo analógico y teosófico. En otras palabras, el índice mismo (el paratexto) estaría mostrando la existencia de un universo armónico y orgánico, donde las anécdotas inscritas en mundos representados aparentemente distintos pueden —o de hecho deben- entenderse como unificadas y, por tanto, como explicables en sus relaciones recíprocas y en sus relaciones con el todo de ese universo; no pueden entonces ser maravillosas ni fantásticas, dado que para ellas existen explicaciones científicas (teosóficas) y, en consecuencia, han dejado de ser problemáticas.

La segunda lectura pertinente se refiere a la diferencia entre el tipo de títulos de ambas partes, es decir entre el de los doce primeros relatos y el de los textos del «Ensayo». Según la clasificación de Genette (2001: 72-79) queda claro que los primeros — todos ellos — caen dentro del grupo de los temáticos, es decir de aquellos que sintetizan el tema o argumento de sus anécdotas. Por el contrario, tanto el título del «Ensayo» como los de sus textos centrales (las diez «lecciones») y los de sus dos textos colaterales (el «Prefacio», el «Epílogo») serían títulos autorreferenciales o remáticos, es decir referidos al género o subgénero literario de cada texto. A su vez, los subtítulos de cada lección serían también temáticos, pero pertenecerían más bien a un discurso científico, por su lenguaje objetivo y denotativo, mucho menos poético que los títulos de los relatos de la primera parte, los cuales poseerían unos referentes mucho más vagos y abiertos a la interpretación. En otras palabras, esta diferencia de discursos en los títulos de las dos partes (más poético el primero y más objetivo o neutro el segundo) mostraría también que, a través de su índice, LFE estaría proponiendo una lectura más científica o imparcial, que explicaría el mundo más subjetivo o personal de los doce primeros textos del libro. Con este tipo de títulos el «Ensayo» serviría entonces como una especie de rectificación de una posible lectura desencaminada y alejada de las intenciones reales del autor, que habría evitado así una interpretación demasiado ficcional de los relatos del primer grupo. ${ }^{18}$

18 Como apunte referido al índice, hay que recordar que tanto la primera edición como la segunda —ambas revisadas por su autor—, y también muchas de las subsiguientes (Lugones, 1906a; 1926; 1981), mostraban el mismo listado de textos sin variación alguna. Por el contrario, otras más recientes (v. Lugones, 1996) han omitido los textos individuales del «Ensayo» y, con ello, han ofrecido un índice que no representaría las intenciones de Lugones ni tampoco el sentido último del libro. 


\subsubsection{La advertencia}

Lo más interesante de este paratexto ${ }^{19}$ es el tono de alarma emocional que deja traslucir, es decir, el componente subjetivo (ausente en otros paratextos más convencionales) que muestra el interés especial del autor de que la segunda edición del libro se lea de una manera determinada y distinta a la primera. Lo propio de este paratexto sería entonces la inclusión de una apelación directa al lector histórico por parte del autor, lo que demuestra de manera especialmente clara la funcionalidad pragmática de los paratextos y, en este caso concreto, el interés de que el lector lleve a cabo una lectura más o menos referencial o mimética de los relatos.

La advertencia contiene también un alto porcentaje de vocablos remáticos («capítulos», «libro», «narraciones») y de otros referidos al nivel empírico de la publicación («editado veinte años ha», «corrientes ahora», «campo de la ciencia») o de la recepción («bondad del lector», «desventajosa para el interés de las mencionadas narraciones»). En este sentido la advertencia, colocada también en las páginas liminares, se convierte en un momento de negociación para esa nueva lectura, producto también de una reflexión sobre el género o el horizonte de expectativas propuesto para el libro.

Finalmente, y aunque Lugones no detalla a qué «ocurrencias» concretas se refiere, el resto de la advertencia parece aludir a los relatos paracientíficos o a otros con las pretensiones científicas del «Ensayo», como puede ser «El origen del diluvio». En cualquier caso, el aviso parece implicar que la primera edición del libro pretendía que la lectura de los relatos y del ensayo fuera una lectura «científica» o verificable, donde todos los relatos y sobre todo los paracientíficos, fueran entendidos como miméticos o realistas en el sentido de que se correspondiesen a la vez con los postulados de las ciencias positivas y ocultas. El hecho de que, según Lugones, el paso del tiempo haya confirmado que algunas de aquellas hipótesis hayan perdido parte de su novedad solo indicaría la veracidad total de las mismas, que así contagiarían de veracidad al resto de las narraciones o compensarían su carga principalmente imaginativa.

19 La advertencia completa era la siguiente: «Algunas ocurrencias de este libro, editado veinte años ha, aunque varios de sus capítulos corresponden a una época más atrasada todavía, son corrientes ahora en el campo de la ciencia. Pido pues, a la bondad del lector, la consideración de dicha circunstancia, desventajosa para el interés de las mencionadas narraciones» (Lugones, 1996: 95). 


\section{2 Paratextos que afectan a partes concretas del volumen}

\subsubsection{Los títulos de los doce primeros relatos ${ }^{20}$}

En este apartado me interesa comentar el sema de extrañeza o singularidad inherente a varios de esos títulos y la naturaleza concreta y definida de la referencialidad de los mismos. En cuanto a «La fuerza Omega», el primer cuento del libro, este puede entenderse como un título epónimo del volumen y por tanto como una pista también para anclar la procedencia y significado del mismo y, con ello, la intención del autor. En efecto, la anécdota de este relato es una ficcionalización de uno de los inventos comentados en la Doctrina Secreta de Blavastky, en concreto el de la máquina de John E. W. Keely (18371898) (Blavatsky, 1978: I, 554-566; Hewitt, 1979: 114-125; Linde, 2014: 59-76). En el contexto que interesa, este cuento y su título estarían entonces iniciando el libro con la propuesta de la posibilidad de nombrar (el primer paso para explicar lo desconocido) una de esas fuerzas nuevas (la «coming force») que circulan en el universo y lo estructuran y que, dado que pueden recibir una primera etiquetación, ya no se presentarían como completamente fantásticas o desconocidas.

El segundo caso sería el de aquellos títulos que en su totalidad o en alguno de sus términos anuncian un argumento con previsibles rupturas de leyes naturales, de fenómenos extraordinarios o, al menos, de cierta singularidad. Aunque no se da en todos los títulos, sí aparece en una cantidad significativa. Claramente se ve por ejemplo en sintagmas como «La lluvia de fuego», «Un fenómeno inexplicable», «El milagro de san Wilfrido» o «El origen del diluvio». Algo semejante se adivina en otros títulos como «El escuerzo», por sus connotaciones legendario-folklóricas, o en «La metamúsica», por su propuesta de algo trascendente a la simple música. Lo mismo puede decirse de «Viola acherontia», por correlacionar las flores y la muerte, o de «La estatua de sal», por la singularidad implícita en el referente del título. En este sentido, cabe afirmar que el tono general de este grupo de títulos sería el de evocar lo no familiar y, más en concreto, lo ajeno al mundo ordinario, preparando así la entrada del lector en un universo distinto de la cotidianeidad y de lo experimentado habitualmente.

20 La bibliografía sobre los relatos individuales de LFE es también relativamente amplia, entre otros: Dabove (2009), Fraser (1996), Fraser (2008), Llanes (2013), Marini (1994), Riva (2005) o Scari (1964). Sin embargo, y salvo algunas excepciones (Castro, 2003; Linde, 2014), son igualmente escasos los comentarios referidos a sus paratextos. 
Finalmente podría comentarse que varios de esos títulos se refieren a conceptos concretos más que a ideas abstractas, lo que permite vincular esos títulos con la intención verificable y específica de la anécdota, que no sería así algo primariamente lírico o simbólico. En esos títulos se producen individualizaciones con artículos determinados y complementos del nombre («La lluvia de fuego», «Los caballos de Abdera», «La estatua de sal»), con adjetivos nominales («La fuerza Omega») o con nombres propios o pretendidamente científicos («El milagro de san Wilfrido», «Yzur», «Viola acherontia»).

Puede afirmarse entonces que el total de estos títulos es un verdadero umbral del mundo extraordinario de los relatos, preparando al lector para leerlos con una mayor suspensión de la credibilidad que si fueran relatos miméticos y, al mismo tiempo, llevando un sema de lo hiperrealista y lo verificable. En otras palabras, cualquier lector que empezara leyendo el libro por el índice, estaría preparándose más o menos conscientemente para la lectura de un grupo de anécdotas donde el autor iba a presentarle un mundo que por un lado remitía al universo de lo extraordinario pero que, por otro, presentaba sus anécdotas con un ropaje de concreción y realismo que hacía de estas algo verificable y literariamente verosímil.

\subsubsection{Cuentos con cambios de título}

En este apartado cabrían tres relatos. El primero sería «Un fenómeno inexplicable», que en su primera versión habría llevado como título «La lycanthropía» y como subtítulo «(cuento)»; ${ }^{21}$ el segundo sería «El escuerzo», que en su primera versión habría llevado el título de «Los animales malditos», y el tercero «Viola Acherontia», que en su versión inicial se había titulado «Acherontia Athropos»(Lugones, 1981: 75, 95, 125). Con los datos conservados al respecto, las explicaciones para estos cambios no pueden pasar más que de hipótesis, con diferentes grados de plausibilidad, pero no por ello dejan de ser menos elocuentes.

Quizá el cambio más fácil de justificar sería el de «Un fenómeno inexplicable», ya que su primera versión se publicó en una revista teosófica y el segundo en un volumen como LFE. La primera versión llevaría entonces un título más específico e inteligible para los lectores más probables de la revista, o sea, los iniciados en el esoterismo, y por ello necesitados también del subtí-

21 Sobre las implicaciones narratológicas de la ausencia de paratextualidad en este relato y sus cercanías con el marco narrativo, pueden tenerse en cuenta las sugerencias de Andrea Castro (2003: 196-197). 
tulo del relato para que, debido a su ficcionalización autobiográfica, no resultara confundido con una anécdota propiamente histórica. Por el contrario, la versión de $L F E$ estaba incluida en un libro con intención proselitista y, por ello, dirigida a un público más general y necesitado también de un título más accesible. El título definitivo resulta quizá más general que el resto de títulos de la primera parte pues, de hecho, es el único cuyo sintagma contiene un artículo indeterminado. Esa indeterminación se convierte en incertidumbre con el adjetivo «inexplicable», que explicita el carácter de interrogante irresuelto típico de lo fantástico-puro.

El título original de «El escuerzo»-«Los animales malditos»- podría referirse a una serie de cuentos con una temática o protagonistas similares; sin embargo, en la cuentística total de Lugones no se encuentra ningún otro cuento de este tipo hasta llegar precisamente a "Los caballos de Abdera», ${ }^{22}$ que podría haber sido escrito para complementar «El escuerzo». En cualquier caso, lo que sí resulta claro y alinea a este título con el resto es su referencia a un animal que las tradiciones populares y literarias han asociado frecuentemente con el misterio y lo ominoso. En este sentido, sería un título que ya predispondría al lector a encontrarse con una anécdota ubicada en un mundo de misterio o de acontecimientos inusuales.

Por su lado, el título «Viola acherontia» parece ganar en precisión y en efectismo al sustituir a «Acherontia atropos», el título original. En precisión por referirse ahora a la flor que es realmente el objeto protagonista de la anécdota, mucho más que el insecto aludido en la primera versión a través de la aparición de la calavera en sus pétalos. Y en efectismo por referirse a una flor inexistente en el mundo real, pero con una nomenclatura que copia una nomenclatura científica establecida, cosa que daría más visos de verosimilitud al final exitoso del experimento del sabio. La retención del término «acherontia» indica, de nuevo, la misma asociación con la muerte y lo ominoso de otros títulos de esa primera parte del libro. ${ }^{23}$ Así pues, en el sintagma del título se fundirían lo científico y lo ominoso, con un resultado que casi puede considerarse emblemático por su combinación de lo hiperreal y lo desconocido.

22 Para una constatación de este dato pueden usarse las dos principales recopilaciones del resto de la cuentística de Lugones, es decir, Lugones (hijo) (1963) y Lugones (2018b).

23 En cuanto al término «acherontia» del título del cuento, quizá convenga recordar que el Aquerón o Aqueronte era uno de los ríos del inframundo o Hades de la mitología griega. 


\subsubsection{Los subtítulos}

Aparte del subtítulo ya comentado [el «(cuento)» de «La lycanthropía»], los otros dos relatos de la primera parte con este tipo de paratexto son «La lluvia de fuego», que lleva el de «Evocación de un desencarnado de Gomorra» $\mathrm{y}$ «El origen del diluvio», que se presenta como la «Narración de un espíritu». En ambos casos son entonces los subtítulos y no los títulos quienes introducen y explicitan la temática esotérica de los cuentos, narrados en todo o en parte por un espíritu o un médium. Es a través de ellos (y no del narrador) como el lector se entera de que ambas voces narrativas proceden de seres fantasmáticos, es decir no miméticos, inusuales e imposibles también en una anécdota realista. En otras palabras, dado que este tipo de voces no suelen ser reconocidas automáticamente por el lector, la lectura debe desambiguarse mediante la identificación de dichas voces, identificación que solo puede proceder de una voz autorial, es decir la del autor implícito y no la de otro narrador, que no podría comunicarse con el lector histórico ni saltar al nivel del paratexto, externo a la diégesis. Evidente es también el hecho de que la utilidad pragmática de ambos subtítulos procede más de su carácter remático que de su contenido, es decir, más de la información de los paratextos sobre el propio formato del relato («evocación», «narración») que del argumento de la historia en sí. Con ellos es el autor quien aumenta la verosimilitud narrativa a la anécdota, pues sin esos subtítulos resultaría mucho más difícil identificar la voz o la perspectiva narrativas correspondientes y al lector le sería también más difícil evitar la confusión. Solo con ellos es posible aclarar completamente el tipo de mundo narrado propio de cada cuento, ya que son quienes informan sobre la identidad de la voz narrativa y su perspectiva frente a la anécdota. Así, este paratexto es entonces una referencia necesaria para adscribir el relato a un género o a otro, para entenderlo como fantástico («El origen») o como maravilloso («La lluvia»). Los subtítulos entonces no pueden haber sido redactados por el narrador sino por el autor implícito, es decir, por el propio Lugones, en cuanto reflexiona y vuelve sobre su propio texto y en cuanto ve cómo puede o debe añadir otras estrategias para hacer legible un par de textos tan atípicos en sus voces narrativas.

\subsubsection{Epígrafes y citas de encabezamientos}

Los dos epígrafes que aparecen en los cuentos de LFE tienen una trayectoria que podemos llamar inversa. Por un lado, el que «Viola acherontia» 
llevaba en su publicación periódica desaparece completamente en el volumen, mientras que el de «La lluvia de fuego» aparece solo a partir de la segunda edición. Al mismo tiempo, los dos son similares en cuanto a su función, en parte por proceder de textos literarios anteriores a LFE y ya consagrados culturalmente por una tradición literaria más o menos longeva.

El epígrafe de «La lluvia de fuego» remite a la intertextualidad bíblica del relato, aunque curiosamente la traducción que lleva a cabo Lugones no parece corresponderse con una lectura literal del versículo en cuestión. ${ }^{24}$ Como quizá se recuerde también, no es el libro del Levítico sino en el Génesis donde se narra la historia de Sodoma y Gomorra, por lo que podría pensarse que el epígrafe puede proceder de alguna versión bíblica desconocida u obedecer a un deseo de encaminar al lector hacia una relectura del texto más o menos distinta de la que el autor supone que fue la lectura de la primera edición. En cualquier caso, con el epígrafe se insiste en los vínculos del cuento con la literatura no positivista y en especial con aquellos momentos en que hay participación de agentes sobrenaturales y presencia de fenómenos extraordinarios. El epígrafe remite de nuevo al origen divino o supracientífico de la lluvia y por ello obliga al lector a anclar su lectura en ese nivel ontológico, que ahora complementaría al puramente esotérico o más mitológico de la primera versión, donde ese epígrafe estaba ausente. ${ }^{25}$

Por su parte, la eliminación del epígrafe de «Viola acherontia» parece no afectar al significado de la segunda versión del cuento, pero también es cierto que este epígrafe y su hipotexto («Le Merchand de Tulipes», de Gaspard de la Nuit) contiene unas alusiones al mundo vegetal y al mundo simbólico y analógico de la Teosofía que hubieran podido facilitar el entendimiento del cuento. ${ }^{26}$ En efecto, en su texto original las palabras de este epígrafe van precedidas de otras referidas a la ausencia de perfume en los tulipanes, es decir a su completa

24 En LFE se lee «"Y tornaré el cielo y la tierra de cobre" Levítico, XXVI, 19». Como digo, en ninguna de las ediciones de la Biblia consultadas para este trabajo aparece lo que podría ser el original literal de esta traducción. En la Vulgata, por ejemplo, el versículo lee: «et conteram superbiam duritiae vestrae. Daboque vobis caelum desuper sicut ferrum, et terram aeneam» (Colunga y Turrado, 1965: 103), que podría traducirse como «Quebrantaré vuestra orgullosa fuerza y haré vuestro cielo como hierro y vuestra tierra como bronce».

25 Aunque las fechas al respecto no están claras, puede recordarse que el Lugones de los últimos años tuvo una conversión al cristianismo que, aunque fuera más cultural que existencial, bien podría explicar la aparición del epígrafe.

26 Me refiero aquí al epígrafe del poema en prosa en el original de Bertrand y al verso que Lugones usa como epígrafe de «Viola»: «La tulipe est parmi les fleurs ce que le paon est parmi les oiseaux. L'une est sans parfum, l'autre est sans voix; l'une s'enorgueillit de sa robe, l'autre de sa queue», y «Une tulipe! s'écria le vieillard courroucé, une tulipe! ce symbole de l'orgueil et de la luxure qui ont engendré dans la malheureuse cité de Wittemberg la détestable hérésie de Luther et de Mélanchton!» (Bertrand, 1868: 37-38; Lugones [hijo], 1963: 94-95). 
maleabilidad, en cuanto pueden estar abiertos a manipulaciones como las que lleva a cabo el científico del cuento. Por lo que se refiere al contenido simbolista, está claro que el epígrafe remite a la cosmovisión teosófica de Lugones, en el sentido de que el tulipán evoca en el texto de Bertrand un mundo superior (el mundo del pecado y de la muerte), de modo semejante a cómo, en «El milagro de san Wilfrido», el lirio convocaba el arrepentimiento y la resurrección.

\subsubsection{Correcciones y variantes}

Para ilustrar este apartado quizá lo más útil será recordar las expurgaciones llevadas a cabo en la versión final de «Un fenómeno inexplicable». ${ }^{27}$ En resumen, esos cambios se refieren a las observaciones del narrador protagonista sobre la fisonomía y psicología de su anfitrión y a las ciencias de raigambre ocultista desde las que se interpretan esos datos. En su conjunto, la desaparición de esa información concreta parece responder a un deseo de economía expresiva, pero también puede explicarse a partir del tipo de lector del libro, menos familiarizado con disciplinas de la «Alta Magia», como la «metoscopia» mencionada por Lugones en la versión periodística. ${ }^{28}$ Obviamente, el conocimiento de esta «ciencia» (ciencia oculta en este caso) por parte del narrador, implica la identificación de este con el típico personaje experto y escéptico de los relatos fantástico-puros. Al final del relato este narrador va a ver cuestionados sus conocimientos con la aparición de un dato extraordinario, que en este caso es la sombra del simio, es decir, una silueta que no se corresponde con el rostro de su anfitrión y que era lo esperable por el narrador-protagonista. En otras palabras, aunque quizá justificadas por razones editoriales, las variantes en estas versiones del cuento no parecen cuestionar su adscripción a lo fantástico-puro, pero sí es claro que la versión final carece de algunos datos que fortalecerían esa adscripción y que, por tanto, mostrarían cómo

27 No se comentan aquí las variantes léxicas entre las dos primeras ediciones de $L F E$, que, aunque abundantes, son de una relevancia limitada y parecen estar simplemente guiadas por un afán de mayor precisión semántica. Al mismo tiempo, parece claro que esta identidad que podemos considerar total entre ambas ediciones parece implicar la conclusión de que para Lugones LFE era ya una obra «cerrada» desde la primera edición, como dejaba claro el carácter circular de su índice. Más relevancia tienen las correcciones de las versiones periodísticas, donde sí quedan claras otras intenciones de Lugones. En otro artículo dedicado principalmente a esta cuestión (Martínez, Godínez y Vargas, 2019), hemos atendido a las variantes de «La estatua de sal», «Viola acherontia» y «El psychon» para concluir, resumiendo, que tales revisiones se refieren sobre todo a la eliminación de datos superfluos o eruditos («El milagro») pero también con cambios importantes en el desarrollo del argumento («Viola», «El Psychon»).

28 Esta disciplina era un método de adivinación centrado en la lectura de las arrugas del cuerpo y de la cara. 
también este tipo de paratextos (las variantes y las correcciones) pueden tener una alta rentabilidad práctica a la hora de condicionar tales taxonomías. Como dato adicional, puede considerarse también que estas variaciones muestran también cómo lo fantástico puede textualizarse de una manera u otra dependiendo del lector pretendido. Por su interés y dado que este conjunto de variantes es prácticamente desconocido, transcribo a continuación los párrafos más interesantes de la versión periodística («La lycanthropía»), marcando en cursivas el texto ausente en la versión de LFE:

Presenté mi carta de recomendación. Mientras aquel hombre leía, pude observarle a mis anchas. Cabeza elevada y calva; rostro afeitado de clergyman [sic en Philadelphia]; labios generosos, nariz austera, ojos fríamente firmes, de un azul muy obscuro; cutis pálida. Respiraba anchamente y a prolongados intervalos. Tenía, pues, ante mí, un hombre de paz, cuya visible energía proyectada hacia la severidad, podía trocarse, al impulso de movimientos afectivos, en ese entusiasmo extático que caracteriza a la mística; pero al mismo tiempo, el valor manifiesto por su epidermis y su respiración, indicaban, dada la «base» del carácter posibles desviaciones hacia el proselitismo, y aun exaltaciones iracundas. Debía de ser un tanto místico. Las protuberancias supercialiares, equilibraban con una recta expresión de tendencias impulsivas, el desdén imperioso de su mentón. En resumen, se trataba de un entusiasta-reflexivo. Definido por sus inclinaciones profesionales, aquel hombre podía ser lo mismo un militar que un misionero. Procedía evidentemente de un seminario jesuita o de un cuartel. Su conjunto resultaba una amalgama de persuasión y autoridad. Era claro que su carácter no tenía más que un doblez, siendo su coyuntura la generosidad. Para llegar hasta su alma sería menester contradecirle por la duda.

Todas estas observaciones de metoscopia, para emplear un término de la Alta Magia, se verificaron con la rapidez a la que me habian acostumbrado persistentes estudios en la ciencia de Gratiolet y Lavater. Me explicaba ya su misantropía. Un misántropo es siempre un entusiasta. Sabía, además del carácter, la manera de tratar a mi hombre, y esto era la mitad del camino. Naturalmente no se trataba sino de un cálculo de probabilidades, pero este cálculo acierta noventa veces sobre cien. Hubiera deseado mirar sus manos para completar mi impresión, mas sólo podía verlas por el dorso.

Enterado de la carta, el dueño de la casa me invitó a pasar. Suprimo las pequeñas formalidades de la introducción, mis expresiones de gracias por la distinción que importaba aquel recibimiento, dadas las manías del personaje. Y llego al momento de la sobremesa, que fue también el de la singular aventura cuya narración he emprendido. Mientras comíamos, no obstante la amabilidad exquisita de mi interlocutor, noté que algo inquietante le preocupaba, (y todo el resto de mi permanencia, hasta la hora de comer, quedó ocupado por mis arreglos personales) Las cejas contraídas, su mirada, invariablemente dirigida hacia un ángulo de la habitación, insinuaba cierta impresión de angustia. Aquella insistencia provocó mi curiosidad y de la manera más disimulada que me fue posible, arrojé una rápida ojeada sobre el rincón. En la mesa fue donde empecé a notar algo extraño. Su mirada invariablemente dirigida hacia un ángulo de la habita- 
ción, manifestaba cierta angustia; pero como su sombra daba precisamente en ese punto, mis miradas furtivas nada pudieron descubrir. Por lo demás, bien podía no ser aquello sino una distracción habitual (Lugones [hijo], 1963: 104-105).

\subsubsection{Contexto e ilustraciones en la prensa periódica}

En cuanto a los paratextos de los relatos con versiones periodísticas conservadas, estos interesan por haber aparecido en fechas muy próximas a la de la publicación del libro (primeros meses de 1906), y por informar por tanto sobre cómo pudo ser también el proceso de presentación y recepción del público más inmediato, y cómo pudieron o no condicionar también un tipo específico de lectura.

En el caso de «La fuerza Omega», la versión más antigua conocida es la de diciembre de 1905, que fue publicada por El Tiempo de Buenos Aires. En ella lo más destacable puede ser la ilustración, ya que las variantes textuales son mínimas. Como puede verse (imagen 1), el dibujante ha seleccionado el momento final del relato, es decir, el momento en que el narrador y su acompañante descubren el cadáver del sabio junto a la máquina y con la masa cerebral

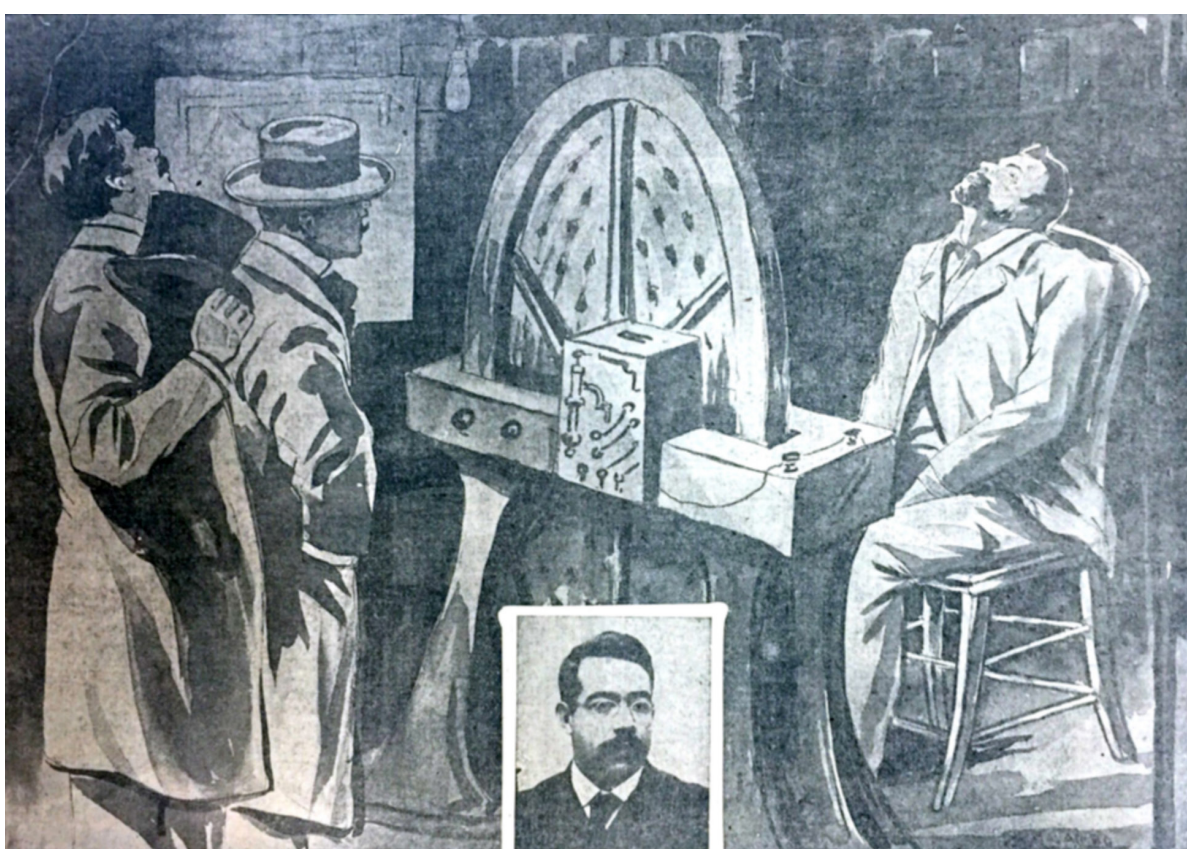

Imagen 1 
esparcida en la pared. Para lo que interesa aquí, el retrato de Lugones inserto en la ilustración informa indirectamente — a través de su vestimenta- de que el mundo del relato que aparece en la ilustración es homólogo y coetáneo al de los personajes de la anécdota. En otras palabras, la ilustración entonces informaría de que «La fuerza Omega» sería antes un relato fantástico o extraño que uno de ciencia ficción, cuyas ilustraciones suelen enfatizar el «novum» o lo distinto de lo coetáneo. Las miradas de los dos amigos del sabio, centradas en los componentes de la tragedia (el cadáver y las vísceras esparcidos por la pared), insisten de nuevo más en el aspecto trágico de la anécdota que en su aspecto no mimético.

La otra ilustración conservada es la de «El milagro de san Wilfrido» (imagen 2), aparecida en Caras y caretas en abril de 1906, que interesa por seleccionar también el momento climático del cuento (la aprehensión de la cabeza del agá por parte de la mano crucificada de san Wilfrido) y por incluir el epígrafe informativo del paréntesis, que indica la procedencia del texto («Del libro Las fuerzas extra$\tilde{n} a s ») \cdot{ }^{29}$ De todos modos, más que la ilustración en sí, en este caso lo más singular puede ser el contexto religioso inmediato de su publicación, pues no hay que olvidar que «El milagro» es un relato hagiográfico y que fue publicado por primera vez el día de Miércoles Santo (15 de abril) de 1897. En 1906 se habría publicado en dos lugares más, en LFE y en el número de Semana Santa de Caras y Caretas. Así visto «El milagro» habría recibido entonces dos lecturas distintas y divergentes en función de su lugar de aparición y de la consecuente duplicación de sus lectores inmediatos. La primera (la de El Tiempo y la de Caras y caretas) habría ocurrido en el marco de la tradición cristiana y la segunda (la de LFE) en el marco del sincretismo religioso propuesto por la Teosofía. Consecuentemente, en las publicaciones periódicas tendríamos un cuento maravilloso-cristiano, en el sentido de que lo extraordinario se explicaría por la intervención de lo divino, y en el libro tendríamos un relato más bien extraño o esotérico, si se entiende que el sincretismo teosófico habría subsumido el universo y la cosmología cristianos. Dicho de otra manera, esa divergencia de paradigmas quedaría confirmada o condicionada por los acompañantes textuales y paratextuales de cada versión, que en la primera serían el conjunto de textos o imágenes periodísticos de índole religiosa tradicional, y en la segunda, todo el conjunto de relatos y paratextos ubicados en $L F E$ y encaminados a producir una lectura teosófica del cuento.

29 En concreto «El milagro» apareció en el número 232 del 7 de abril de la revista junto a otras colaboraciones de contenido religioso (v. Lugones, 1906b). Las colaboraciones de Caras y caretas eran principalmente crónicas o reportajes fotográficos («Pasión y muerte de Jesús», «Domingo de ramos», «Jueves Santo», «Viernes Santo», aunque también se incluían simples crónicas («Un sermón de Viernes Santo», «Sábado de Gloria») o felicitaciones episcopales («La bendición arzobispal»). 


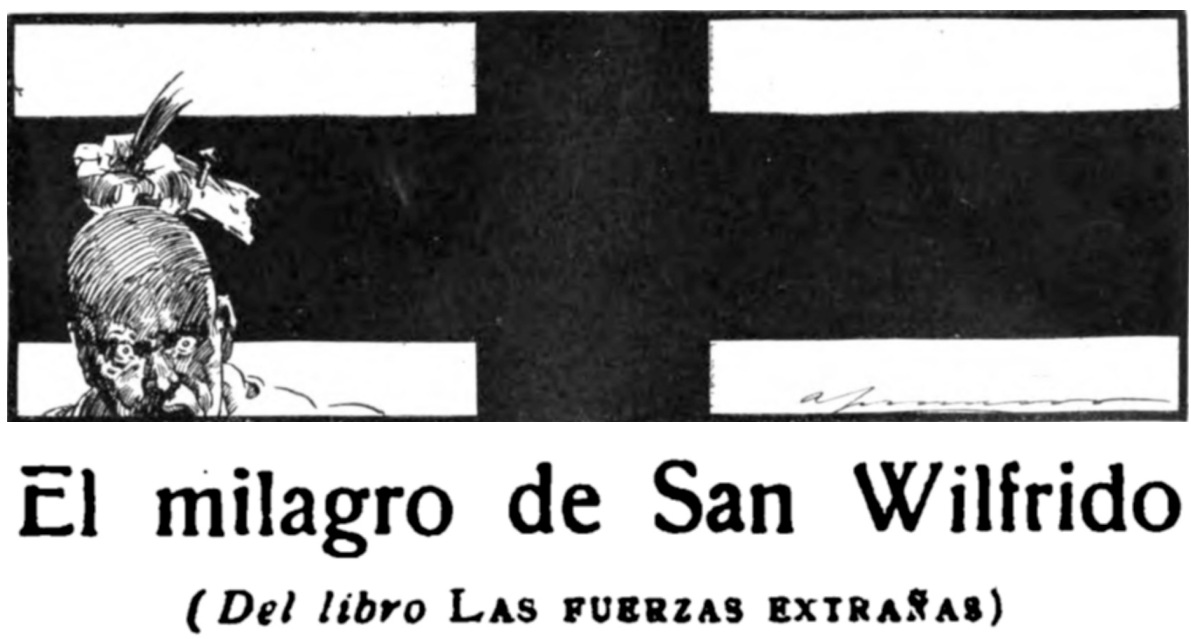

Imagen 2

5.2.7 Los paratextos del «Ensayo»

Como ya se ha visto, el título completo del «Ensayo» («Ensayo de una cosmogonía en diez lecciones») marca un claro distanciamiento con los títulos de los primeros doce relatos del volumen, pues por un lado es remático y por otro se inscribe más en un discurso de carácter científico que en uno propiamente imaginativo. También los semas de cada vocablo de este paratexto apuntan en la misma dirección. Así «Ensayo» suele remitir a un género literario alejado de la ficción y más cercano a lo filosófico y a interpretaciones verificables de lo real; por su lado «cosmogonía» aludiría a una serie de publicaciones más o menos contemporáneas o contextuales de LFE como El origen de las especies (1859) de Darwin, la Doctrina secreta (1888) de Blavatsky o la Filogenia (1884) y Mi credo (1906) de Florentino Ameghino. ${ }^{30}$ Por su lado, las «diez lecciones» y el prefacio y el epílogo que las flanquean llevarían a pensar en la obsesión pitagórica que Lugones (y Blavastky) tienen a la hora de explicar el universo, en este caso por el uso de números recurrentes como el diez o el doce. Finalmente, el término «lecciones» insistiría en el carácter didáctico de estos textos, una perspectiva superpuesta a la más creativa y emo-

30 Estas publicaciones, y muchas otras de la segunda mitad del XIX y comienzos del XX, proponían una explicación global y científica de todo lo real. Florentino Ameghino (Argentina, 1854-1911) fue un paleontólogo muy popular en su tiempo, muy admirado también por Lugones y cuyas ideas pueden estar también detrás de alguna de las teorías cosmológicas de LFE (v. Lugones, 1915). 
cional de los relatos de la primera parte, que así quedarían también subsumidas por estos diez textos de índole magisterial y que, por ello y por su origen en un narrador autodiegético, apuntan a una voz autorial que va a explicitarse aún más en las notas del «Ensayo».

Los títulos y subtítulos de las diez lecciones del «Ensayo» conforman una serie de parejas que combinan lo remático y lo ordinal por una parte (cada uno de los títulos) y lo temático y lo científico-objetivo por otra (los subtítulos). Se presentan además con una gradación interna fácilmente perceptible, pues la serie empieza con «El origen del universo» y concluye con el capítulo dedicado a «El hombre», que sería algo así como la culminación de ese proceso evolutivo. Describirían entonces una trayectoria progresiva y evolutiva muy en la línea de las teorías científicas de entonces y, por ello, muy difícil de desvincular de estos contextos para los lectores informados y contemporáneos de Lugones, para quienes esa perspectiva cosmológica totalizante era también la propuesta científica definitoria del volumen. Entre esas lecciones quizá la más interesante aquí sería la lección quinta, pues su título («Nuestra teoría ante la ciencia») es paralelo al de otros dos ensayos programáticos publicados por Lugones en la revista Philadelphia unos años antes y con ese adjetivo posesivo referido a los partidarios de la Teosofía. ${ }^{31} \mathrm{Al}$ final de ese conjunto de lecciones la cosmología resultante es una explicación total acerca de la naturaleza y funcionamiento del universo y de sus componentes, es decir, la explicación de las fuerzas o energías que justifican los argumentos de la primera parte, sean estos ocultistas, paracientíficos, mitológicos, etc. Sería consecuentemente la explicación que resolvería las incógnitas de la primera parte y que harían de todas y cada una de ellas acontecimientos miméticos o extraños, pero no maravillosos o fantásticos. Desde este punto de vista, el narrador autodiegético del «Ensayo» subsumiría a todos los narradores previos de cada cuento, que en su momento habrían planteado esos acontecimientos como maravillosos o fantásticos.

Las notas que aparecen en el «Ensayo» (en las dos ediciones del libro) son de especial interés y complejidad, pues por un lado se presentan como producto de la reflexión del narrador autodiegético del «Ensayo» pero, por otro, como todas las notas, remiten a un nivel de autorreflexión de la escritura que las ubica muy cerca del autor implícito, ya que, como todos los paratextos, las notas están también más vinculadas al proceso de construcción del texto total que a su particular diégesis interna. Así, estas notas, aparte de llamar la

31 El primero, titulado «Nuestro espíritu científico», apareció el 7 de agosto de 1900, y el segundo («Nuestras ideas científicas») el 7 de noviembre 1901. Los dos se recogen en Lugones (2018a: 111-134). 
atención por su abundancia (un promedio de cinco por «lección»), están redactadas desde una perspectiva también magisterial o, si se quiere, supra-magisterial, por matizar y corregir las afirmaciones del sabio intradiegético que enuncia las diez lecciones. Por otro lado, y como no podría ser de otra manera, las coincidencias temáticas con otros escritos del autor empírico (o sea el Lugones autor de textos diferentes a LFE) son igualmente llamativas, en especial en aquellos momentos en que insiste en el enfrentamiento entre las ciencias positivas y las ciencias ocultas, y también en aquellos en los que explícitamente muestra esa militancia ocultista. Como manifestaciones de esta dimensión supradiegética de las notas pueden mencionarse la escritura de las mismas desde un plural colectivo (el «nosotros» de los seguidores de la Teosofía) o el carácter remático de las mismas, con frecuentes autorreferencias a su proceso de escritura o a su inserción en el «Ensayo». En resumen, lo que queda claro es que estas notas, en sus contenidos y sus perspectivas, se alzan sobre la diégesis del propio ensayo y se ubican en las funciones propias de los paratextos, por ser reflexiones autoriales sobre el texto principal. Es cierto que, en puridad, las notas proceden del narrador homodiegético, pero sólo aparecen una vez trascurrida y cerrada la secuencia diegética; por ello, si se insiste en su carácter metaliterario o en sus similitudes con otros textos ensayísticos de Lugones, hay que pensar que es una voz autorial y no una voz diegética la que está detrás de ellas. Esta voz sería, en definitiva, la voz del autor implícito, la del autor generado por las necesidades del propio texto de LFE. Dicho de otra manera, al final, a través de la perspectiva generada por esas notas, sería el autor implícito quien ofrecería la última palabra sobre la naturaleza de las fuerzas y energías que explicarían las anécdotas de todos y cada uno de los relatos de LFE, convirtiéndose en la voz que, como en los relatos catalogados como extraños, eliminaría el interrogante y, con ello, su catalogación como fantásticos. ${ }^{32}$

\section{Conclusiones}

Tras esta exposición, parece posible afirmar entonces que, al igual que ocurre con los relatos miméticos, los paratextos pueden condicionar y de hecho condicionan la lectura efectiva de las narraciones no miméticas, haciendo

32 Como adición final a estas observaciones sobre los paratextos del «Ensayo» podría recordarse que este aloja también un esquema explicativo (Lugones, 1996: 266) que no es propiamente un texto, por incluir componentes grafemáticos, pero que tampoco vamos a considerar aquí como paratexto, por darse dentro del texto principal. En cualquier caso, su pertenencia al discurso científico insistiría de nuevo en el tono de todo el ensayo. 
que incluso haya que ajustar o al menos relativizar las taxonomías aplicadas hasta el presente. En el caso de LFE, títulos como «Un fenómeno inexplicable» o «El milagro de san Wilfrido», o subtítulos como «Evocación de un desencarnado de Gomorra» («La lluvia de fuego») o «Narración de un espíritu» («El origen del diluvio»), no solo dirigen la lectura en una dirección concreta, sino que pueden definir de antemano el carácter fantástico o maravilloso de la anécdota y dejar así muy poco espacio al lector para distanciarse de la propuesta del autor del paratexto. Los paratextos, además, no serían solo los catalogados por Genette, sino que también incluirían las vicisitudes editoriales de los textos principales que, como en el caso de «El milagro de san Wilfrido» o las dos versiones de «Un fenómeno inexplicable», mostrarían que ese contexto histórico concreto puede también condicionar la categorización del relato, bien sea ocasionando una doble lectura del mismo o insistiendo en los recursos propios de una de esas tipologías. El estudio de los paratextos puede entonces complementar y corregir la rigidez de las taxonomías de la literatura fantástica, que habitualmente han tomado como criterios principales el tipo de mundo creado y la infrasciencia del narrador, del protagonista o del personaje-testigo.

También ha debido quedar claro que LFE sería un volumen excepcional para comentar estas dimensiones de lo fantástico, pues la diacronía de sus textos ficcionales y la variedad funcional de sus paratextos generan en todo el volumen una serie de relecturas y autorreflexiones que pocas veces aparece en relatos fantásticos aislados o en las recopilaciones habituales, en general mucho más homogéneas que LFE. La utilidad y complejidad de LFE se derivarían, por ejemplo, de los cambios y correcciones llevadas a cabo al corregir algunas versiones periodísticas y al preparar la segunda edición del libro, que implicaría también una revisión de la primera y, a través de paratextos como la advertencia o algunas adiciones y correcciones, una información sobre la intención mimética o no mimética del libro. Lo que se desprende al final sería la composición de un volumen con unos doce relatos iniciales de categorización no mimética diferente (fantástico-puro, mitológico, extraño, etc.), pero subsumidos por el ensayo final y el índice, que indicarían un universo o cosmovisión ocultistas que explicarían «científicamente» todas esas anécdotas. La acumulación de voces magisteriales y de paratextos remáticos en el «Ensayo» elevarían a este por encima del simple nivel de la diégesis y lo acercarían más bien al nivel del autor implícito, justificando por un lado el título del «Ensayo» del último texto del volumen, pero también la intención proselitista de todo el conjunto. Finalmente, quedaría claro que los paratextos ayudan a 
entender y revelan el concepto mismo de autor implícito, como mostraría la intervención de este en los subtítulos de los relatos ocultistas, en las notas del «Ensayo» y la ordenación del índice que, obviamente, no pueden ser obra de los narradores, siendo a la vez exigencias que los propios textos imponen al autor empírico para hacer legibles los textos.

Para cerrar, hay que afirmar entonces que si toda la literatura y en especial la ficción se lee en función de los paratextos, los relatos no miméticos y particularmente los fantásticos tampoco pueden desprenderse de este condicionante y, por ello, están llamándonos a una revisión de algunos de los criterios taxonómicos usados hasta ahora. Y aunque tampoco se trata de postular un relativismo absoluto o una invalidación de las clasificaciones más frecuentes, la verdad es también que esos criterios se refieren a una lectura abstracta o ideal del texto, y que solo teniendo en cuenta los paratextos se hará una clasificación en función de su lectura empírica o real, tal como de hecho la ha presentado el autor histórico a través del autor implícito.

BibLiografía

AltmanN, Ulrike et al. (2014): «Fact vs. fiction - how paratextual information shapes our reading processes», Social Cognitive and Affective Neuroscience, núm. 9/1, pp. 22-29.

ARÁN, Pampa (2000): «Fantástico, esoterismo, ideología: Leopoldo Lugones», Escritos. Revista del Centro de Estudios del Lenguaje, núm. 21, pp. 123-140.

BARCia, Pedro Luis (1981): «Composición y temas de Las fuerzas extrañas», en Leopoldo Lugones, Las fuerzas extrañas, Ediciones del 80, Buenos Aires, pp. 9-45.

BARRENeCHEA, Ana M. (1972): «Ensayo de una tipología de la literatura fantástica», Revista Iberoamericana, núm. 33/80, pp. 391-403.

BERG, Mary (1968): «Para la bibliografía de Lugones», Hispanic Review, núm. 36/4, pp. 353-357.

Bertrand, Aloysius (1868): Gaspard de la Nuit, Binceourde, París.

Blavatsky, Helena P. (1978): The Secret Doctrine, 3 vols., The Theosophical Publishing House, Madras/Londres.

Воотн, Wayne C. (1961): The Rethoric of Fiction, University of Chicago Press, Chicago.

CAstro, Andrea (2003): «La ciencia en el fantástico ambiguo: “Un fenómeno inexplicable", de Leopoldo Lugones», RILCE, núm. 19/2, pp. 193-204.

CIRUTI, John (1975): «Leopoldo Lugones: The Short Stories», Revista Interamericana de Bibliografia/Review of Inter-American Bibliography, núm. 25/2, pp. 139-149.

Colunga, Alberto, y Laurentio Turrado (eds.) (1965): Biblia Vulgata, Biblioteca de Autores Cristianos, Madrid. 
DABove, Juan Pablo (2009): «“La cosa maldita”: Leopoldo Lugones el gótico imperial», Revista Iberoamericana, núm. 75/228, pp. 773-792.

Fletcher, Glynn Lea (1981): El cuento modernista en revistas y diarios argentinos: 18901910, Texas Tech University, Lubbock.

FrASER, Benjamin (2008): «Un neuro-musicólogo antes de su tiempo: Discursos actuales del sonido a través de dos cuentos de Leopoldo Lugones», Hispania, núm. 91/4, pp. 794-804.

Fraser, Howard M. (1996): «Apocalyptic Vision and Modernismo's Dismantling of Scientific Discourse: Lugones's “Yzur"», Hispania, núm. 79/1, pp. 8-18.

GASPARINI, Sandra (2008): «De oradores, polémicas y distopías. La emergencia de la fantasía científica», Anales del Instituto Americano. Nueva Época, núm. 11, pp. 143160.

- (2012): Espectros de la ciencia. Fantasías científicas de la Argentina del siglo XIX, Santiago Arcos, Buenos Aires.

Genette, Gérard (2001): Umbrales, trad. Susana Lage, Siglo XXI, Buenos Aires.

GHIANo, Juan Carlos (1985): «Lugones y Las fuerzas extrañas», en Ángel Flores (ed.), El realismo mágico en el cuento hispanoamericano, Premià, Tlahuapan, pp. 25-41.

Haywood Ferreira, Rachel (2011): The Emergence of Latin American Science Fiction, Wesleyan University Press, Middletown.

HewitT, Sandra A. (1979): «Leopoldo Lugones and Theosophy: a Study of Sources and Influences in Las fuerzas extrañas», Harvard University, Cambridge. Tesis Doctoral.

JACKSON, Rosemary (1981): Fantasy: the Literature of Subversion, Methuen, Londres.

JENSEN, Theodore W. (1975): «El pitagorismo en Las fuerzas extrañas de Lugones», en Donald A. Yates, (ed), Otros mundos, otros fuegos. Fantasía y realismo mágico en Iberoamérica. Memoria del XVI Congreso Internacional de Literatura Iberoamericana, Latin American Studies Center, East Lansing, pp. 259-307.

KôNIG, Irmtrud (1984): La formación de la narrativa fantástica hispanoamericana en la época moderna, Peter Lang, Frankfurt am Main.

LERMON, Miguel (1969): Contribución a la bibliografía de Leopoldo Lugones, Maru, Buenos Aires.

Linde, Pilar (2014): Leopoldo Lugones. Mitos y arquetipos de Las fuerzas extrañas, Universidad de Málaga, Málaga.

Llanes, Manuel (2013): "Religión secundaria en "Los caballos de Abdera"», El catoblepas, núm. 142, disponible en <https: / / www.elcatoblepas.es / 2013/n142p03. htm> [31-5-2020].

López, María P. (2004): Lugones, entre la aventura y la Cruzada, Colihue, Buenos Aires.

Lugones, Leopoldo (1906a): Las fuerzas extrañas, Moen y Hemanos, Buenos Aires.

- (1906b): «El milagro», Caras y caretas, núm. 232 (segundo trimestre, año IX), p. 392.

- (1915): Elogio de Ameghino, Otero y Co, Buenos Aires.

- (1926): Las fuerzas extrañas, M. Gleizer, Buenos Aires.

- (1981): Las fuerzas extrañas, ed. Pedro Luis Barcia, Ediciones del 80, Buenos Aires.

- (1996): Las fuerzas extrañas, ed. Arturo García Ramos, Cátedra, Madrid.

- (2018a): Estudios esotéricos, ed. Pedro Luis Barcia, Docencia, Buenos Aires. 
- (2018b): Cuentos desconocidos, ed. Pedro Luis Barcia, Docencia, Buenos Aires.

LugonEs, Leopoldo [hijo] (1963): Las primeras letras de Leopoldo Lugones, Centurión, Buenos Aires.

Maclean, Marie (1991): «Pretexts and Paratexts: the Art of the Peripheral», New Literary History, núm. 22/2, pp. 273-279.

Marini PALmieri, Enrique (1994): «Yzur, mono sabio: sobre un cuento de Leopoldo Lugones», Alba de América, núm. 12/22-23, pp. 245-256.

MartíneZ, José María (2010): «¿Subversión u oxímoron? La literatura fantástica y la metafísica del objeto», RILCE, núm. 26/2, pp. 363-382.

- (2019): «La arquitectura de Las fuerzas extrañas, de Leopoldo Lugones: la analogía universal y las taxonomías de lo fantástico», Bulletin of Hispanic Studies, núm. 96/5, pp. 534-552.

—, Jonathan GodínEz y Itzel VARGAS (2019): «Sobre las variantes textuales de Las fuerzas extrañas (y la intertextualidad de "Un fenómeno inexplicable")», Anales de Literatura Hispanoamericana, núm. 48, pp. 143-203.

Mathew, Imogen (2018): «Can the Preface Broker a Realist Pact in Fantastic Fiction?», Australasian Journal of Victorian Studies, núm. 22/1, pp. 82-97.

Millet, Gilbert, y Denis Labbé (2005): Le fantastique, Belin, París.

Morales, Ana María (2004): «Transgresiones y legalidades. Lo fantástico en el umbral», en José Miguel Sardiñas y Ana María Morales (eds.), Odiseas de lo fantástico, CILF, México, pp. 25-37.

NAHARro-CALderón, José María (1994): «Escritura fantástica y destrucción realista en Las fuerzas extrañas de Leopoldo Lugones», Hispanic Review, núm. 61/1, pp. 23-34.

NÁjERA RAmírez, Karla Gabriela (2019): «Viejas como el miedo»: las ficciones fantásticas en el Río de la Plata de 1906 a 1940. Antecedentes, desarrollo y consolidación de un género, Colegio de San Luis, San Luis Potosí. Tesis doctoral.

Ojalahti, Anna (2017): Paratexts in Fantasy: Paratextuality, Intertextuality and Rhetoric in Robin Hobb's Fool's Quest, University of Tampere. Trabajo Final de Máster.

QuereIllac, Soledad (2016): Cuando la ciencia despertaba fantasias: prensa, literatura y ocultismo en la Argentina de entresiglos, Siglo XXI, Buenos Aires.

ReIs, Carlos, y Ana Cristina M. Lopes (2002): Diccionario de narratología, trad. Ángel Marcos de Dios, Almar, Salamanca.

Riva, Reynaldo (2005): «Yzur, Funes y el inmortal: una convergencia metafísica», Revista Chilena de Literatura, 66, pp. 47-62.

Roas, David (ed.) (2001): Teorías de lo fantástico, Arco/Libros, Madrid.

Ruiz Barrionuevo, Carmen (1995): «Las fuerzas extrañas, de Leopoldo Lugones», en Enrique Pupo-Walker (ed.), El cuento hispanoamericano, Castalia, Madrid, pp. 171-190.

SABIA, Saïd (2005): «Paratexto. Títulos, dedicatorias y epígrafes en algunas novelas mexicanas», Espéculo. Revista de Estudios Literarios, núm. 31, disponible en < http:/ / webs.ucm.es/info/ especulo/ numero31/ paratext.html > [1-5-2020].

SCARI, Robert M. (1964): «Ciencia y ficción en los cuentos de Leopoldo Lugones», Revista Iberoamericana, núm. 30/57, pp.164-187.

SchmiD, Wolf (2013): «Implied Author», en Wolf Schmid (ed.), The living handbook of 
narratology, disponible en <http:/ / www.lhn.uni-hamburg.de/node/58.html> [26-5-2020].

Semilla, María Angélica (1985): «La organización narrativa de "La estatua de sal"», en Ángel Flores (ed.), El realismo mágico en el cuento hispanoamericano, Premià, Tlahuapan, pp. 86-98.

SPECK, Paula (1976): «Las fuerzas extrañas: Leopoldo Lugones y las raíces de la literatura fantástica en el Río de la Plata», Revista Iberoamericana, núm. 42/96, pp. 411-426.

Speratti Piñero, Emma S. (1957): «La expresión en Las fuerzas extrañas, de Leopoldo Lugones», en Ana María Barrenechea y Emma Speratti Piñero (eds.), La literatura fantástica en Argentina, Imprenta Universitaria, México, pp. 1-36.

Todorov, Tzvetan (1970): Introduction à la litterature fantastique, Seuil, París.

ZuCKerman, Alex (1975): «Las fuerzas extrañas, de Leopoldo Lugones: análisis crítico», en José Olivio Jiménez (ed.), Estudios críticos sobre la prosa modernista hispanoamericana, Eliseo Torres, Nueva York, pp. 236-253. 